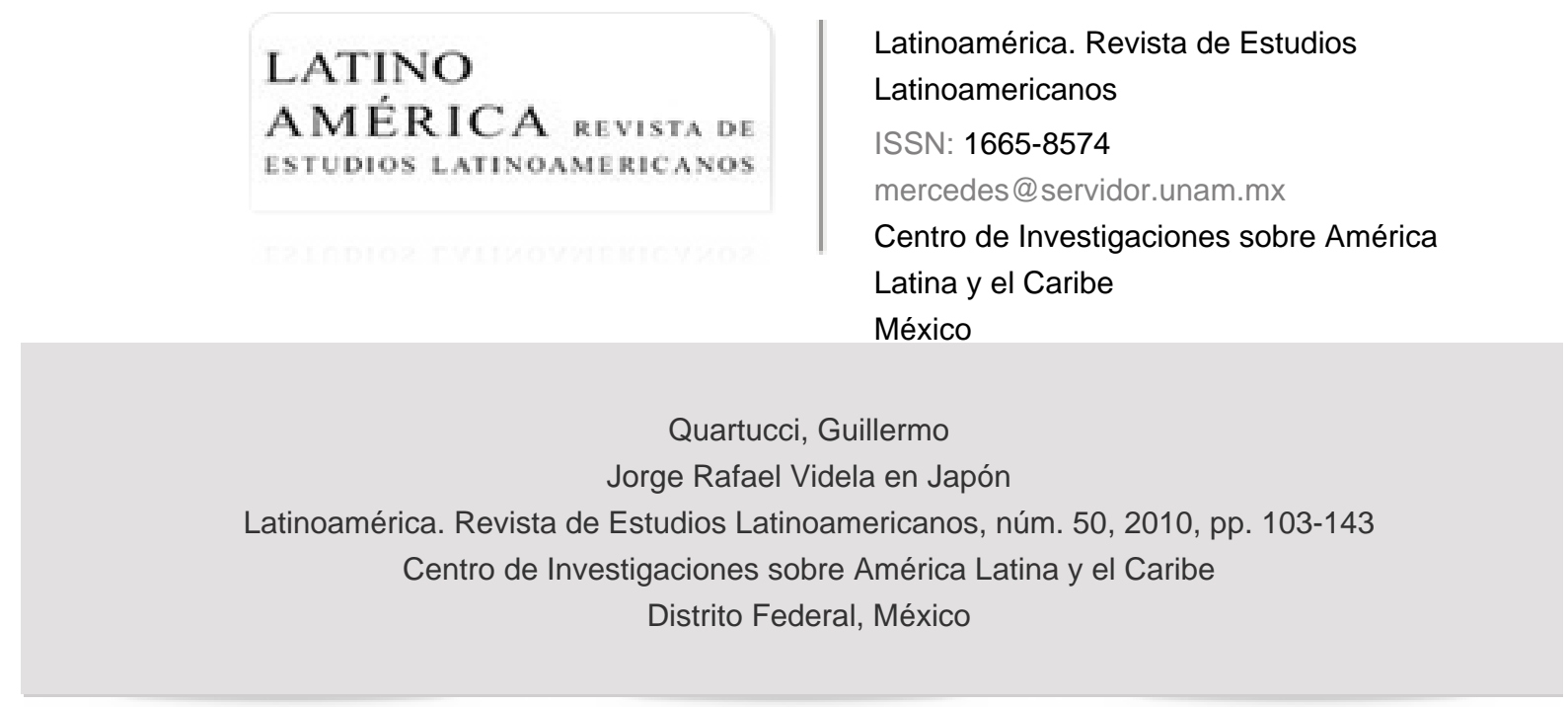

Disponible en: http://www.redalyc.org/articulo.oa?id=64014997007

Cómo citar el artículo

- Número completo

- Más información del artículo

- Página de la revista en redalyc.org

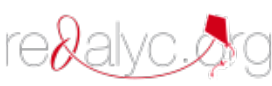

Sistema de Información Científica

Red de Revistas Científicas de América Latina, el Caribe, España y Portugal Proyecto académico sin fines de lucro, desarrollado bajo la iniciativa de acceso abierto 


\title{
Jorge Rafael Videla en Japón
}

\author{
Guillermo Quartucci*
}

Resumen: La visita a Japón, en octubre de 1979, del teniente general Jorge Rafael Videla, dictador de Argentina entre 1976 y 1981, constituye un hecho histórico poco conocido y menos analizado por los especialistas. Basándose en las notas periodísticas de la época publicadas por el periódico japonés en lengua inglesa, The Japan Times, el artículo analiza las notas publicadas a lo largo de la visita de Videla y su comitiva, así como tres fotografías (desde la perspectiva semiótica), tendientes, sin excepción, a maquillar la verdadera cara represora del régimen castrense que encabezaba Videla.

Palabras Clave: Dictadura argentina, Videla visita Japón.

ABSTRACT: The visit to Japan, in October 1979, of Lieutenant-General Jorge Rafael Videla, Argentina's dictator between 1976 and 1981, is a historical event not very well known and less analyzed by experts. Based upon a series of notes published in the English newspaperThe Japan Times, edited in Tokyo, in October 1979, this article analyzes the covering of Videla's visit and his accompanying team, as well as three photographs (from a semiotic perspective)which illustrates the notes. The apparent purpose of the visit was to make up the repressive face of the Argentinian military Junta headed by Videla, both by Argentinian's representatives based in Japan and the newspaper.

KeY words: Argentina dictatorship, Videla visits Japan.

* Centro de Estudios de Asia y África, Colegio de México (gquartu@colmex.mx). 
LOS VIAJES DE VIDELA

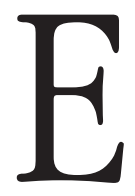

1 presidente de facto Jorge Rafael Videla, integrante, junto con Luis Emilio Massera y Orlando Ramón Agosti, de la Junta Militar que gobernó con mano de hierro la Argentina, entre 1976 y 1981 (en este año fue sustituida por otra Junta), el periodo más sangriento del llamado Proceso de Reorganización Nacional, estaba más que deseoso de romper con el aislamiento internacional derivado de la pésima reputación, adquirida a raíz de la brutal política represiva que impuso en el país desde el golpe de Estado que derrocó a Isabel Perón el 24 de marzo de 1976.

El primer viaje al exterior del general Videla se concretó en marzo de 1977 con la visita a Perú, donde gobernaba un militar de tendencias ideológicas similares, el general Francisco Morales Bermúdez, quien recibió con beneplácito al presidente argentino. Se trató de una visita que no requirió de mayores trámites diplomáticos, dada la postura de ambos mandatarios frente al combate a la subversión y la coincidencia en los métodos, en el marco de la entonces muy en boga teoría de la seguridad nacional.

Dos meses después de este primer viaje, en mayo de 1977, Videla hizo una visita protocolaria a Venezuela, gobernada en ese momento por Carlos Andrés Pérez, del partido Acción Democrática, quien desconfiaba de la política represiva imperante en Argentina y quien no deseaba manchar su figura de demócrata al recibir a un general cuya feroz imagen empezaba a difundirse por el mundo. Sin embargo, gracias a los muy buenos oficios del embajador de Argentina en Caracas, Héctor Hidalgo Solá, un hombre importante en las filas de la Unión Cívica Radical de su país quien mantenía buenas relaciones con Videla, la visita pudo llevarse a cabo. Videla y Pérez llegaron inclusive a firmar declaraciones conjuntas relacionadas con algunos conflictos que afligían a las naciones latinoamericanas, en las que enfatizaron, sobre todo, las situaciones neocoloniales (como Malvinas) que persistían en la región y la necesidad de intensificar la cooperación económica. Videla, con este viaje, pretendía revertir la imagen negativa de la Junta Militar en el exterior, y aprovechar la buena relación de Pérez con el gobierno de Estados Unidos para que intercediera frente a James Carter, en lo referente a la violación de los derechos humanos, que el presidente nor- 
teamericano denunciaba con firmeza. La visita de Videla constituyó un relativo éxito, pero tuvo la desastrosa consecuencia de que el 18 de julio de ese año, en un viaje que Hidalgo Solá hizo a Argentina, éste fuera secuestrado y pasara a engrosar la lista de los ya por entonces miles de desaparecidos. Se habló de una "interna" entre videlistas (partidarios de Videla) y masseristas (partidarios de Massera), en la cual ambas facciones se disputaban el poder y pretendían liderar una salida democrática limitada para Argentina, a la cual se había referido Hidalgo Solá, en Caracas, en una conferencia de prensa mantenida después de la visita de Videla, conferencia que desató la ira del masserismo.

El tercer viaje de Videla ${ }^{1}$ lo transportó a las antípodas, nada menos que a Japón, donde arribó el 8 de octubre de 1979. Habían pasado más de dos años desde su viaje a Venezuela. La imagen sangrienta de la Junta, lejos de disiparse, como se había esperado a raíz del triunfo de la selección argentina en el Mundial de Futbol del '78, se había intensificado, en parte por efecto de las denuncias de las organizaciones defensoras de derechos humanos, dentro y fuera de Argentina, que aprovecharon el evento deportivo para difundir en la prensa internacional las tropelías que se cometían a diario en el país. Las Madres de Plaza de Mayo eran ya conocidas más allá de las fronteras de Argentina y ningún país de la órbita europea, incluidos la Unión Soviética y sus satélites, habría deseado mostrar abiertamente tener algún tipo de relación con la dictadura argentina, menos aun el gobierno de Estados Unidos. ${ }^{2}$

La distancia y duración del viaje desde Argentina hasta Japón, tomando en cuenta estos escollos, hacían aconsejable a Videla y su comitiva utilizar una ruta transpacífica alternativa que, al evitar los aeropuertos americanos o europeos, los transportara a Japón con alguna escala en islas del Pacífico Sur.

1 El cuarto y último viaje del dictador sería al año siguiente, o sea, 1980, cuando visitó China acompañado de una muy nutrida comitiva integrada por uniformados, empresarios, banqueros, y la mayoría de las esposas de todos ellos.

2 Si quedan dudas al respecto, véanse los documentos desclasificados del Departamento de Estado disponibles en Internet, miles de páginas que contienen los detallados informes que se enviaban desde la embajada de Estados Unidos en Buenos Aires, en los que se hablaba de los centros clandestinos de detención, las torturas, las desapariciones forzadas de personas y, en general, del ambiente represivo que se respiraba en todos los ámbitos de Argentina entre 1976 y 1983. 
Un factor favorable a la visita de Videla es que hacía muy poco se había jugado en Japón la Copa Mundial Juvenil de Futbol, en la que el equipo de Argentina resultó triunfador y la figura de Diego Armando Maradona quedó impresa en el libro de los grandes ídolos del país asiático. De alguna manera, sólo por este hecho, Argentina se había vuelto popular entre los japoneses, y la Junta encabezada por Videla, ni lerda ni perezosa, decidió aprovechar la coyuntura para hacer una visita oficial al País del Sol Naciente. Por otra parte, el 3 de febrero de 1979 se había inaugurado en Buenos Aires, con la presencia de Videla, en el elegante barrio de Palermo, el Jardín Japonés (de dos hectáreas) cedido a la ciudad por la comunidad nipona en Argentina, lo cual mostraba las buenas relaciones que esta comunidad mantenía con el régimen militar. ${ }^{3}$

En la concreción del viaje de Videla desempeñaron un papel fundamental tres factores: el anticomunismo exacerbado del gobierno conservador de Japón, en manos desde 1955 del Partido Liberal Demócrata (PLD), donde se habían reciclado numerosos personajes involucrados en los años del militarismo que había llevado al país al desastre de la Segunda Guerra Mundial; el apogeo de la Guerra Fría, que mantenía en vilo a esa parte del mundo tras la victoria militar de Vietnam socialista, en 1975, y el éxito económico del Japón de posguerra, que empezaba a hacer creer a sus dirigentes que podían constituirse en polo económico independiente, para lo cual necesitarían intensificar sus relaciones económicas con países productores de materias primas a cambio de tecnología. Argentina podía muy bien servir a este último objetivo.

El elemento clave para concretar la visita de Videla fue el embajador de Argentina en Japón, contraalmirante Carlos Jaime Fraguío, quien, desde la presentación de las cartas credenciales, en septiembre de 1976, había tejido una malla de relaciones con funcionarios del gobierno y llevado a cabo una campaña tendiente a limpiar - sin demasiado esfuerzo, dadas las simpatías japonesas por el régimen militar argentino- la imagen de la Junta en Japón.

3 Hasta hace muy poco tiempo, transcurrido más de un cuarto de siglo, era posible ver en el Parque Japonés la placa del día de su inauguración, que recordaba al dictador argentino. Finalmente, fue retirada. 
Fraguío, nacido el 11 de mayo de 1926, pertenecía a la misma generación que el almirante Eduardo Emilio Massera (1925) y el vicealmirante Luis María Mendía (1925-2007), los tres integrantes de la Armada argentina, los dos últimos relacionados con el plan de exterminio de prisioneros políticos, que incluía los tristemente célebres "vuelos de la muerte" en los cuales se les arrojaba anestesiados desde aviones de la Marina al río de La Plata o a las aguas del Atlántico Sur. Entre febrero y septiembre de 1976, cuando Fraguío presentó las cartas credenciales como embajador de Japón, había estado al frente de la Dirección Naval, cargo por el cual tuvo la responsabilidad en los centros clandestinos de detención de la Escuela de Mecánica de la Armada (ESMA) y la Escuela de Suboficiales de Infantería del Mar. En 1987 fue beneficiado con la Ley de Punto Final, dictada durante el gobierno de Raúl Alfonsín. ${ }^{4}$ Asimismo, Fraguío había participado en su juventud, al mando de uno de los aviones que partían de la Base Naval de Puerto Belgrano, en los bombardeos de junio de 1955, a la Plaza de Mayo de Buenos Aires, que dejaron varios centenares de muertos civiles y fueron el preámbulo del derrocamiento del segundo gobierno de Juan Domingo Perón, en septiembre de ese mismo año. Su momento le llegó, sin embargo, con el golpe de 1976 que derrocó a Isabel Perón. Fraguío nunca ocultó su naturaleza golpista. ${ }^{5}$ Después de desempeñarse como embajador en Japón, en la década de los noventa, fue nombrado presidente de la Asociación argentino-japonesa y estuvo bastante activo ofreciendo conferencias en distintas instituciones del país como "especialista" en temas de Japón.

4 El 20 de marzo de 1987, a dos años de los juicios a las juntas por el gobierno de Alfonsín, el Consejo de Almirantes, entre los que se encontraba Fraguío, publicó un desplegado en el diario $L a$ Nación de Buenos Aires, donde se reivindicaba la actuación en los "años de fuego". Poco después se dictó la Ley de Punto Final, y todos ellos se sustrajeron a las manos de la justicia. Sin embargo, en 2003, con la declaración de nulidad de las leyes de Punto Final y Obediencia Debida, se reabrieron las causas por violación a los derechos humanos. Desde diciembre de 2006 Fraguío se encuentra recluido bajo prisión preventiva a la espera del juicio oral por la Causa EsMa. Véase la nota de Gabriel Sued aparecida en el diario La Nación de Buenos Aires, 22 de diciembre, 2002, p. 12.

5 Véase al respecto el reportaje del 2 de octubre al artista plástico peronista Daniel Santero, en el marco de un seminario sobre política y ficción llevado a cabo en el Parque de España, en Rosario, Argentina, que apareció en el diario La Capital de Rosario. En http://www.lacapital. com.ar/2005/10/02/seniales/noticia_233857.shtml (fecha de consulta: 5 de junio, 2007). 
Como ya se ha dicho, Videla y su nutrida comitiva llegaron a Japón en la mañana del lunes 8 de octubre de 1979, donde permanecerían hasta el viernes 12, es decir, cinco días. La comitiva estaba integrada por la esposa de Videla, Alicia Raquel Hartridge de Videla; el ministro de Relaciones Exteriores y Culto, brigadier mayor (R) Carlos W. Pastor y su esposa, María Isabel Hartridge de Pastor; el ministro de Economía, José Alfredo Martínez de Hoz y su esposa, Elvira Bullrich de Martínez de Hoz; el secretario general de la Presidencia, general de brigada Alberto Crespi y su esposa Estela Graciela del Perpetuo Socorro de Crespi; el jefe de la Casa Militar, contraalmirante Walter Colombo; el director nacional de Ceremonial, embajador Juan Carlos Katzenstein; el secretario de Planeamiento, brigadier José Miret; el secretario de Información Pública, general de brigada Antonio Llamas; el secretario de Intereses Marítimos, contraalmirante Carlos Noé Noguera, además de funcionarios del Banco de la Nación Argentina (Juan M. Ocampo, presidente, y Jorge Prat Gay, vicepresidente), del Banco Central de la República Argentina, líderes empresariales y hasta un sacerdote saleciano, Humberto Cavaliere. A ellos se unieron en Japón el embajador, contraalmirante Carlos Jaime Fraguío y su esposa, Martha Ares de Fraguío, y el representante en Tokio del Banco de la Nación Argentina, Osvaldo R. Agatiello. ${ }^{6}$

Se desconoce el costo total de esta visita de Videla a Japón, pero si nos atenemos a la siguiente misión del presidente de facto, en 1980, a la República Popular China (el cuarto y último de los viajes internacionales que realizaría), cuyo monto ascendió a más de un millón de dólares, podemos pensar que la misión a Japón, país mucho más caro, ha de haber costado al erario públicoargentino bastante más que esa cifra.

Videla había sido declarado "huésped de Estado" por el gobierno japonés, de modo que a su llegada a Tokio se instaló con su esposa en el elegante Palacio de Akasaka o Geihinkan (Pabellón de Huéspedes Ilustres), inmenso edificio de es-

6 En el Archivo DiFilm, de Buenos Aires (archivo fílmico de Cine y Televisión, en 16 y 35 mm., Fotográfico, Hemeroteca, Radio y Posters) se conserva una película en color, con sonido magnético, de alrededor de 18 minutos de duración, que sigue paso a paso las actividades de Videla y su comitiva en Japón. En http://www.difilm.com.ar (fecha de consulta: 5 de junio, 2007). 
tilo neobarroco europeo, donde son hospedados dignatarios mundiales de altísimo nivel que llegan a Japón.

El periódico en lengua inglesa que se edita en Tokio desde 1897, The Japan Times, siguió paso a paso las actividades de Videla en Japón, excepto el 11 de octubre, día que por suceder a un feriado nacional (Día del Deporte, 10 de octubre) el periódico no se publicó. The Japan Times es editado por una empresa independiente y es el periódico al que, habitualmente, las embajadas extranjeras recurren para proporcionar información sobre sus respectivos países o anunciar el festejo de su día nacional. La edición de donde hemos tomado toda la información referente a la visita de Videla es la edición postal internacional. Incluyendo la nota en la que se anunció, con una semana de anticipación, la llegada de Videla y la reproducción del editorial de otro periódico el día posterior a la partida, el número de notas fue de $11 .^{7}$ Asimismo, la cobertura gráfica de la visita es muy abundante: 12 fotos en total, más el retrato del embajador Fraguío y del presidente de la Asociación argentino-japonesa, Sr. Shigeo Nagano, que acompañan las notas respectivas. Sin lugar a dudas, se trata de una cobertura excepcional para este tipo de acontecimientos, lo que demuestra que tanto la parte argentina, que contrató los espacios, como también la japonesa, habían puesto grandes expectativas en la visita. ¿A qué se deberían semejantes expectativas?

\section{The JAPAN TIMES Y LA PRESENCIA De VIDELA EN JAPÓN}

La primera nota que anunciaba la visita de Videla a Japón apareció en The Japan Times (como se ha dicho, escaparate favorito de las misiones diplomáticas en el País del Sol Naciente), el miércoles 3 de octubre con el título de "La misión argentina busca estrechar vínculos con Japón” (Doc. I). En ella, el embajador Fraguío comenta a los periodistas, reunidos en conferencia de prensa en la residencia oficial de la embajada, las razones que motivan a Videla a viajar a Japón, y entre las referencias obligadas a las relaciones de amistad de larga data que unen a ambos países ("si bien es necesario fortalecerlas", agrega), destaca

En el Anexo presentamos la traducción de todas las notas cuyos títulos van precedidos de un número romano. 
la necesidad de estimular la cooperación económica bilateral, verdadero motivo de la visita. Fraguío esboza, además, el calendario de actividades de Videla y las reuniones que mantendrá durante su estancia en Tokio. "El gobierno argentino desea invitar a las empresas japonesas a que inviertan en el país de manera permanente, así como a introducir tecnologías y desarrollar recursos naturales", concluye la nota.

La edición del 8 de octubre, día del arribo de Videla, dedica dos páginas completas a la visita del presidente. La nota central (Doc. II), encabezada por grandes letras que rezan "El presidente de Argentina llega hoy a Japón", con el subtítulo de "Se espera que firme acuerdos para impulsar las relaciones bilaterales", va acompañada de una foto de medio cuerpo del dictador argentino y su esposa, muy sonrientes y distendidos, él vestido de civil, con camisa blanca y moño, muy lejos del uniformado personaje adusto asociado con su figura. La nota se refiere a Videla como "el presidente de Argentina" y en ningún momento hace referencia a su grado de teniente general, como tampoco usa el "contraalmirante" para referirse a Fraguío, a quien por error llaman "Fraguilo". Esto marca la tónica de lo que habrá de ser la cobertura de la visita: nada de fotos de uniformados, a pesar de que la comitiva, como se vio, estaba integrada casi exclusivamente por militares de las tres armas. Todas las fotos que se publicarán de Videla en días subsiguientes lo mostrarán invariablemente de civil y muy alegre, reunido con el emperador Showa (Hirohito) y la emperatriz Kojun (Nagako), con el primer ministro Masayoshi Ohira e incluso, en una insólita presentación en público, en una tienda departamental, que más adelante comentaremos. La intención es clara: había que limpiar a Videla de la imagen que recorría el mundo de dictador militar, para convertirlo en un civil normal y amante esposo, enviando así a la sociedad japonesa, poco afecta a los uniformes después del fiasco de la Segunda Guerra Mundial, el mensaje de que Videla no era el personaje atroz que se estaba difundiendo en el mundo.

Sin la menor referencia a la violación a los derechos humanos, la desaparición forzada de personas, la existencia de centros clandestinos de detención, las torturas a que son sometidos los presos políticos, los cientos de miles de exiliados que han debido abandonar la Argentina, ya por entonces ampliamente 
publicitados por la prensa y medios políticos internacionales (la Junta llevaba ya casi cuatro largos años en el poder), esta nota de The Japan Times, así como las de días sucesivos, evitarán tocar el tema. A lo más que se atreve es a referirse escuetamente al "golpe de 1976 que arrebató la presidencia a Isabel Perón".

A los obvios objetivos económicos de la misión encabezada por Videla - dice la nota que hay en Argentina tres proyectos en curso (que analizamos más abajo) que requerirán de la colaboración financiera y tecnológica de Japón, así como la urgente necesidad de que Japón importe productos agrícolas de Argentina-se suma la enigmática aseveración por parte del embajador Fraguío de que "Argentina en la actualidad tiene como urgente prioridad mejorar la relación política" de ambos países, quizá en referencia a la preocupación por lo que consideran el avance del comunismo después de Vietnam. De ello y de la "convulsionada Indochina" hablarán a puertas cerradas Videla y Ohira en uno de los encuentros, según filtraciones a la prensa.

Los tres proyectos económicos en curso a los que hace referencia la nota son: la expansión de la acería estatal somisa (Sociedad Mixta Siderurgia Argentina), la electrificación del ferrocarril estatal Roca y el desarrollo de la pesca en la región patagónica, lo cual resulta muy extraño en un gobierno interesado, particularmente, en deshacerse de las empresas estatales. Lo supieran o no los japoneses, lo que tenían en mente Videla y Martínez de Hoz con esta misión era conseguir el capital para modernizar somisa y los ferrocarriles con miras a su posterior privatización, lo que en realidad sólo pudo concretarse en los años noventa con Carlos Saúl Menem. Por su parte, Martínez de Hoz, ligado directamente a ACINDAR, una acería privada, maquinaba la forma de conseguir para su empresa los mejores contratos de proveedora de una somisa modernizada con capital japonés, como en efecto ocurrió.

Es muy sintomática una de la fotos que ilustra la nota, la cual muestra la Pirámide de Plaza de Mayo, espacio habitual de manifestaciones políticas de diverso signo en Argentina, que reclaman para sí el significado histórico del monumento. En esta foto, la Pirámide, resignificada en esos días por las luchas de las Madres de Plaza de Mayo difundidas en el mundo entero, muestra a sus espaldas el Cabildo (casa de gobierno durante la Colonia), en lugar de la Casa 
Rosada (actual palacio de gobierno), evitando así cualquier eventual asociación con el peronismo, que había hecho un uso muy hábil del edificio, en especial uno de los balcones, donde se presentaban ante la multitud Perón y su esposa Evita. Pirámide más Cabildo son, según el pie de la foto, "símbolos de la nacionalidad argentina", una identidad totalmente alejada de cualquier connotación peronista.

LOS MENSAJES DE BIENVENIDA DE LAS EMPRESAS JAPONESAS

Es interesante analizar el contenido de los mensajes de beneplácito con que los grandes consorcios japoneses dieron la bienvenida al dictador Videla, en inserciones pagadas en The Japan Times. Da qué pensar que sea en el aviso de Toyota la única oportunidad en que aparece el grado de "teniente general" aplicado a Videla. Ilustra el aviso una imagen de un auto fabricado por la empresa, el Celica Liftback.

Una calurosa bienvenida

a

S. E. el Teniente General Jorge Rafael Videla, Presidente de la República Argentina

En ocasión de su visita de Estado a Japón

TOYOTA

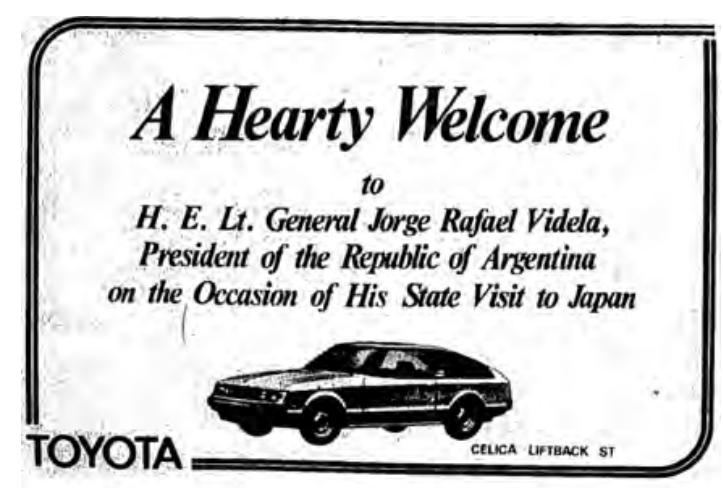


Las siguientes empresas, en orden alfabético, también dieron la bienvenida a Videla:

\author{
Bienvenido \\ S.E. Jorge Rafael Videla \\ Presidente de la República Argentina \\ C. ITOH \& CO., LTD MITSUI \& CO., LTD \\ MARUBENI CORPORATION NISSHO-IWAI CO., LTD \\ MITSUBISHI CORPORATION SUMITOMO CORPORATION
}

(SUMITOMO SHOJI KAISHA, LTD)

La compañía de seguros Yamaichi, beneficiaria directa de los acuerdos económicos que más tarde se firmarían, pagó el siguiente aviso:

Yamaichi extiende una sincera bienvenida

a Su Excelencia el Presidente

de la República Argentina Jorge Rafael Videla

y su esposa

en ocasión de su visita de Estado a Japón

YAMAICHI SECURITIES CO., LTD

Por último, K. Uyeda, tienda especializada en la venta de perlas, recibe así a Videla, en un aviso ilustrado con iperlas!:

\title{
iiBienvenido!!
}

\section{S. E. Jorge Rafael Videla, Presidente de la República Argentina}

Desde 1884

K. Uyeda

Tienda principal: frente al Anexo del Hotel Imperial

Sucursal: Galería del Hotel Imperial

Hay también dos avisos de bienvenida a Videla pagados por la Compañía Argentina de Navegación Intercontinental, S.A.C.I.F. (CANISA) y por ELMA, S. A. (Líneas Marítimas del Estado) que no reproduciremos aquí. 


\section{DOS NOTAS FIRMADAS POR SUS AUTORES}

Con el título de "Solicitamos a Japón formar parte del desarrollo" (Doc. III), el embajador Carlos Jaime Fraguío inicia su nota citando los vínculos históricos que han unido a Argentina con Japón, desde la firma del Tratado de Navegación y Amistad de 1898, que posibilitó, entre otras cosas, la inmigración de japoneses a la Argentina, quienes, en ese momento (1979), junto con sus descendientes, integraban una colectividad de unas 40 mil almas.

El párrafo más significativo de la nota de Fraguío, el que muestra de manera más clara la ideología del régimen castrense argentino, y del amplio sector civil que lo apoyaba, es el siguiente:

A raíz del rápido proceso de modernización, mi país se convirtió en el más homogéneo de América Latina, con profundas raíces en Europa, una clase media altamente letrada y un sistema de bienestar social avanzado.

El muy discutible concepto de "pueblo homogéneo" utilizado por Fraguío estaba en consonancia con un pensamiento muy en boga, en esos momentos, entre los miembros del partido gobernante en Japón, por el cual se atribuía el "milagro económico" japonés al hecho de que su pueblo era, al igual de lo que pretendía Fraguío para Argentina, "homogéneo", cuando en realidad coexistían allí varias minorías. ${ }^{8}$ Asimismo, Fraguío marcaba una diferencia fundamental, muy cara al pensamiento conservador de su país, entre Argentina y el resto de América Latina: Argentina es más europea (y por consiguiente "blanca") que el resto de las sociedades latinoamericanas (morenas y mestizas). Por otra parte, la famosa clase media argentina, "altamente letrada", como informa Fraguío, y el sistema de bienestar social avanzado -aseveraciones bastante discutibles, incluso para esas fechas- habían surgido como consecuencia del gobierno peronista

8 A principios de los años ochenta del siglo xx, el primer ministro de Japón, Yasuhiro Nakasone, provocó un escándalo internacional al afirmar públicamente que el archipiélago japonés era un "portaviones imposible de hundir" gracias a la homogeneidad de su pueblo, a diferencia de Estados Unidos, donde la diversidad racial y la presencia de los negros harían que su predominio empezara a menguar. 
denostado por los militares argentinos, especialmente la Armada, a la cual pertenecía Fraguío. Lo único que no se atrevió a expresar en su nota el embajador argentino es que su país gusta definirse - como no se cansaban de repetir Videla y su cohorte en esos años-como occidental y cristiano, quizá por deferencia a sus anfitriones, orientales y budo-shintoístas.

Otro párrafo significativo de la nota, el que muestra de manera clara los pilares en los que se apoyaba la ideología del llamado Proceso de Reorganización Nacional, surgido como consecuencia del golpe del 24 de marzo de 1976 es el siguiente:

A pesar de las crisis, Argentina [... enfrenta la tarea de restaurar la ley y el orden en el marco de una democracia fuerte, así como de construir una economía eficiente basada en el sistema de libre mercado.

"Crisis", "restaurar la ley y el orden", "democracia fuerte" y, sobre todo, "libre mercado", lemas favoritos de la derecha argentina, son esgrimidos una y otra vez a lo largo de las últimas décadas para manipular la opinión y justificar su desdén por un auténtico orden democrático, manifestaciones contundentes que, sin hacer referencia directa a "golpe", "represión", "suspensión de las garantías constitucionales" y "lucha patriótica" - realidades todas en la Argentina gobernada por un régimen de facto como el de Videla - mandaban un mensaje al gobierno de Japón, también partidario, aunque de manera infinitamente más sutil, de la "mano dura". Sin embargo, la clave estaba en la definición del modelo económico al que aspiraba la clase política argentina que había propiciado el golpe, a la cual pertenecía el súper ministro de Economía que acompañaba a Videla en su visita a Japón, y que iniciaría un ciclo de consecuencias nefastas para la Argentina que se continúa hasta nuestros días: Alfredo Martínez de Hoz, pionero de la ideología neoliberal impuesta a rajatabla en América Latina en los años subsiguientes.

A continuación, Fraguío exhibe, sin demasiada sutileza, la verdadera cara de la misión argentina en Japón, o sea, los objetivos económicos, destacando, en este contexto, "el papel significativo que juega la Cámara de Comercio argentinojaponesa", todo ello disfrazado de nobles conceptos que nadie se atrevería a discutir, como amistad, entendimiento mutuo, sincero sentimiento de afecto entre los dos pueblos y demás estereotipos propios del lenguaje diplomático. 
En este mismo sentido transcurre la otra nota de autor que aparece en The Japan Times de ese día -segundo de la visita de Videla a Japón-la cual se titula "Colocando la piedra fundamental de una amistad en crecimiento" (Doc. IV), firmada por Shigeo Nagano, presidente de la Asociación nipo-argentina.

A las palabras de bienvenida a Videla siguen las consabidas consideraciones históricas en que se basaba la relación de amistad de casi un siglo entre Argentina y Japón, países ubicados en las antípodas. Es particularmente interesante la referencia a un hecho significativo, que, según Nagano, fue un hito en dicha relación. Citamos el párrafo:

En particular, los japoneses están sumamente agradecidos a Argentina por el hecho histórico de que buques de guerra como el Nisshin y el Kasuga, cedidos por Argentina, contribuyeron como fuerza fundamental a la victoria de Japón en la Guerra Ruso-japonesa [1904-1905].

En un artículo titulado "Naves argentinas en la guerra ruso-japonesa", su autor, Carlos A. Manus, reconstruye de manera minuciosa la historia de los dos acorazados citados por Nagano. En virtud de los Pactos de Mayo de 1902, Argentina y Chile se vieron obligados a reducir su flota de guerra. Ante el inminente conflicto con Rusia, Japón necesitaba reforzar sus fuerzas navales, para lo cual decidió adquirir en secreto, a espaldas de la Dieta (Parlamento nipón), estos dos buques que todavía no habían salido de los astilleros Ansaldo, en Génova, Italia, y ya habían sido bautizados como Mariano Moreno y Bernardino Rivadavia. En Japón, para evitar que se difundiera que la compra se había hecho en secreto se decía que los buques habían sido "cedidos" por el gobierno argentino, presidido por Julio A. Roca, en su segundo mandato. En realidad, Japón los compró a Argentina a precio de costo, pagando 14 millones 937 mil yenes a través del Banco Yokohama. El capitán de navío Manuel Domecq García hizo entrega formal de los acorazados en Génova, el 7 de enero de 1904 y los acompañó hasta

9 En http://www.clubdelprogreso.com/index.php?sec $=04 \_06 \&$ texto $=14 \&$ fot $=41$ (fecha de consulta: 8 de junio, 2007). 
Japón, donde participó, como observador, en la Batalla de Port Arthur, que consagró la victoria definitiva de Japón sobre Rusia. Testimonio de estos hechos es el libro que publicó algunos años más tarde..$^{10}$

Posteriormente, ya con el grado de almirante, Domecq García fue promotor de la Liga Patriótica Argentina, surgida inmediatamente después de los sangrientos sucesos de la Semana Trágica de 1919, donde hubo una violenta represión de obreros por las fuerzas de seguridad del Estado. La Liga, con el lema de Ley y Orden, reunió a las personalidades más conservadoras y reaccionarias de la sociedad de Buenos Aires, y su objetivo fue, mientras actuó, silenciar a los inmigrantes que engrosaban las filas obreras y ponían, según ellos, en peligro la identidad de la patria. Anarquistas y judíos fueron blanco preferido de sus persecuciones.

En su nota, sin embargo, Shigeo Nagano omite otro hecho que en su momento tuvo una gran repercusión en las relaciones entre Argentina y Japón - luego de una breve ruptura a raíz de la Segunda Guerra Mundial-, como fue el envío, en 1949, por parte del gobierno de Juan Domingo Perón de un buque cargado de alimentos y medicinas, que aliviaran la terrible situación a que había sido reducido el país después de la derrota. Quizá se trató de una "deferencia" de Nagano hacia los huéspedes argentinos, antiperonistas viscerales.

A continuación, Nagano hace referencia a las buenas relaciones comerciales entre los dos países, con Argentina como exportador de productos agrícolas y Japón, de maquinaria, transportes y plantas industriales. Según Nagano, la fórmula está dando sus frutos, dada la falta de recursos naturales de Japón (en especial, alimentos) y la tradicional ubicación de Argentina en el orbe como productor de alimentos y materias primas.

\section{LOS ACUERDOS ECONÓMICOS}

En una larga y tediosa nota no firmada del mismo 8 de octubre, quizá de la pluma del equipo de especialistas de The Japan Times, cuyo largo título es "Crecimiento altamente favorable en las inversiones internas guía la actividad económica por

${ }_{10}$ Manuel Domecq García, Guerra ruso-japonesa 1904-1905, Buenos Aires, Ministerio de Marina, 1917. 
el camino de la recuperación" (Doc. V), se presenta un minucioso análisis de los avances económicos del primer trimestre de 1979 en los diversos sectores de la producción de Argentina. Al parecer (y esto queda en manos de los especialistas en historia económica), las cifras favorables, las primeras en los más de tres años de la dictadura militar, que se había hecho con el poder para implantar un modelo económico privatizador, con la machacona excusa del combate a la subversión y a las ideas extranjerizantes, son las que impulsaron a Videla a viajar a Japón para conseguir préstamos y promocionar la política económica de Martínez de Hoz, que, como ya se ha dicho, integraba su comitiva.

La nota, entre otras, es ilustrada por una fotografía de las cataratas de Iguazú, si bien el texto no hace referencia en ningún momento al sector turístico. Sí se menciona en cambio el crecimiento del sector de la aviación civil internacional, pues por esos años, con el peso argentino muy sobrevaluado en relación con el dólar (lo que se denominó la "plata dulce"), las clases medias favorecidas viajaban compulsivamente por el mundo, regresando con todo tipo de artículos de lujo adquiridos en el exterior. Este enorme flujo de personas hacia afuera no se correspondía con el ingreso de turistas provenientes del exterior pues, además de que el país resultaba carísimo, la dictadura militar no estaba interesada en recibir visitantes que, eventualmente, podrían enterarse de lo que estaba sucediendo en el país en materia de represión. En ese sentido, la lección del Mundial ' 78 había sido aprendida.

La vocación neoliberal y privatizadora que promovía la Junta estaba en contradicción, sin embargo, con el impulso que en apariencia quería darle a empresas estatales como somisa y Ferrocarriles Argentinos, que no cesaban de estar presentes en los mensajes de la comitiva de Videla al gobierno, a los bancos y a las empresas de Japón, cuando se refieren a la necesidad de modernizar el sector del acero y del transporte ferroviario, así como impulsar desde el gobierno la industria de la pesca en el sur patagónico.

En este sentido, el encuentro de Videla con el primer ministro Masayoshi Ohira, mantenido en el palacio de Akasaka y recogido por The Japan Times el 10 de octubre con el título de "El presidente argentino solicita más inversiones" (Doc. VII), giró alrededor de las demandas de Videla al sector privado japonés 
de que invirtiera en Argentina en diversos sectores de la producción, si bien no dejó de lado la cuestión política de la paz en el mundo, de la cual tanto Ohira como él se declaraban férreos defensores. Incluso Videla se atrevió a decir que "Argentina se está abocando a la 'democratización' de sus instituciones políticas y sociales, y está determinada a servir de 'intermediaria' entre el Norte rico y el Sur pobre". En ningún momento, el periódico japonés comenta estos exabruptos del dictador. Al contrario, parece dar firme crédito a sus palabras, no obstante la difusión mundial que los crímenes aberrantes del régimen castrense argentino habían tenido, en especial a partir del Mundial ' 78.

La siguiente nota, del mismo día que la anterior, se titula "Búsqueda de un acuerdo arancelario" (Doc. VIII), y en ella se habla por primera y única vez de las actividades de José Alfredo Martínez de Hoz en Japón. En su entrevista con su homólogo japonés, Ippei Kaneko, el ministro argentino de Economía le solicitó que hiciera más expeditas "las negociaciones para alcanzar un acuerdo arancelario entre los dos países". Solicitó asimismo que "Japón suministre asistencia financiera y cooperación técnica para la expansión de [... s somisA, la electrificación de los trenes suburbanos, el mejoramiento del sistema de telecomunicaciones y la construcción de plantas procesadoras de pescado", afirmaciones filtradas por fuentes confidenciales del gobierno japonés. Un observador perspicaz no habría dejado pasar la oportunidad de evidenciar el contrasentido de una solicitud financiera destinada a expandir el sector público en boca de un ministro firme partidario del adelgazamiento del Estado. El reportero de The Japan Times no parece darse por enterado.

La nota "Argentina gestiona inversiones extranjeras a fin de modernizarse" (Doc. IX) informa sobre la conferencia de prensa que mantuvo el Dr. Juan M. Ocampo, presidente del estatal Banco de la Nación Argentina -quien acompaña a Videla en su misión-, donde se refirió a la necesidad que tiene Argentina de inversiones extranjeras para modernizar su estructura industrial. Asimismo, da cuenta de los acuerdos firmados por la institución que preside con el Banco de Importaciones y Exportaciones de Japón, del cual recibe un préstamo por el monto de 10 mil millones de yenes ( 45 millones de dólares, al cambio de ese momento), y con el Banco de Tokio, por 1.8 mil millones de yenes (8 millones de dólares). 
El viernes 12 de octubre, día de la partida de regreso de Videla a Argentina, The Japan Times publica en la primera plana la nota titulada "Videla y Ohira acuerdan incrementar la 'sociedad' en varias áreas" (Doc. X). En la segunda entrevista, que mantuvieron el día anterior, Videla y Ohira vuelven a insistir en la cooperación que como "socios" mantendrán los dos países, no sólo en lo económico, sino también en lo político (icombate al comunismo?). Videla, en la conferencia de prensa que mantuvo esa misma tarde en el Club Nacional de Prensa, se mostró muy satisfecho con los resultados de su visita a Japón e informó de la firma de dos acuerdos, uno de intercambio cultural y el otro de cooperación tecnológica. La nota informa también de la misión japonesa que, como resultado de dichos acuerdos, muy pronto visitará Argentina, para estudiar la viabilidad de cooperar financieramente en la expansión de somisA, la electrificación de los ferrocarriles, la instalación de plantas procesadoras de pescado y otros proyectos en curso del gobierno militar. En ese sentido, puede aceptarse que la misión ha sido muy "fructífera", como lo expresó Videla.

\section{LAS NOTAS DE DOS PERIÓDICOS}

The Japan Times traduce al inglés parte de las notas editoriales de dos periódicos muy importantes de Japón en la sección Comentarios de prensa. La primera de ellas (Doc. VI) es publicada el 9 de octubre y corresponde al periódico Tokyo Shinbun, con un tiraje de 620 mil ejemplares. La nota comienza refiriéndose a la tradicional relación de amistad que ha unido a ambos países en ocho décadas ininterrumpidas, cimentada con la visita de buena voluntad a Argentina del príncipe heredero Akihito y su esposa Michiko, en 1968 (durante el gobierno de facto de Onganía), y en 1978, del canciller Sunao Sonoda. En el aspecto económico, la nota apoya a Argentina en sus demandas a Japón de que importe mayor volumen de productos agrícolas, tomando en cuenta que el futuro de Japón en el terreno alimenticio es bastante incierto. La nota se cierra deseando que el "gobierno moderado de Argentina, bajo el liderazgo del presidente Videla, logre alcanzar una mayor estabilidad", evidenciando así que no desconoce lo que está pasando en Argentina, incluida la versión por entonces muy difundida dentro y 
fuera del país, de que el liberal Videla era un moderado frente a los nacionalistas duros encabezados por Massera.

La reproducción de la nota editorial del diario Mainichi Shinbun (con un tiraje de 4 millones de ejemplares diarios, el tercero de Japón), publicada el sábado 13 de octubre (Doc. XI), cuando ya Videla había partido, va más lejos que la anterior al tratar de legitimar a la dictadura argentina con estas palabras:

Argentina ha venido enfrentando grandes dificultades en tratar de superar, con el régimen militar que tomó el poder en 1976, la alta inflación, así como la inestabilidad política y social.

El régimen militar ha ido ganando paulatinamente el reconocimiento de otros países conforme su situación se iba estabilizando.

The Japan Times, un diario habitualmente moderado en sus expresiones políticas, con la cita de estas dos notas editoriales aparecidas en órganos colegas, evitó comprometerse con cualquier manifestación que pudiera ser interpretada como crítica o apoyo al régimen castrense argentino. Tampoco en su sección Readers in Council, el correo de lectores de The Japan Times, en el que habitualmente se oyen voces disidentes con la línea del periódico que sí se publican, apareció nada que hiciera referencia a la violación sistemática a los derechos humanos que padecía, desde hacía tres años, Argentina y que ya era conocida en el mundo entero. Seguramente hubo muchas, pero el diario prefirió evitarlas. El porqué de esta actitud es algo que queda a la interpretación de los analistas.

\section{TRES FOTOGRAFÍAS}

La visita de Videla tuvo también una amplia cobertura fotográfica en The Japan Times durante los días en que se produjo. Algunas de estas fotografías acompañan las notas y son relativamente inocuas, pero hay tres que se destacan de las demás y son las que analizamos a continuación.

El miércoles 9 de octubre, en la página 3 del diario, aparece una foto obviamente retocada que acentúa su irrealidad, y que muestra a Videla y a su esposa sentados en una sala con el emperador Hirohito y su esposa, la emperatriz Nagako. 
Las dos mujeres ocupan el sofá central y miran sonrientes a la cámara, la esposa del dictador con anteojos oscuros muy evidentes. A su derecha, muy tieso y serio, sentado en un sofá individual, está Hirohito, que evita mirar a la cámara, y frente a él, a la izquierda de la emperatriz, también sentado en un sofá individual, Videla se muestra relajado y sonriente. Los cuatro están vestidos a la usanza occidental, en evidente posición de posar para la foto. Ningún detalle nos informa que estamos en Japón. No hay exotismo, pues ni siquiera el arreglo floral que aparece a la derecha de la foto, sobre una mesita, semeja una ikebana tradicional.

Esta escena, fuera del espacio y del tiempo, con los personajes involucrados sin los atributos de su imagen habitual (Hirohito y la emperatriz de kimono, Videla de militar, serio y circunspecto, generalmente solo, raramente acompañado de su esposa), nos envía el mensaje de que estos cuatro apacibles y sonrientes personajes son, en realidad, como nosotros y que nada de lo que pueda achacárseles ahora, o se les haya achacado en el pasado, es verdad.

La siguiente fotografía, publicada el viernes 12 de octubre, es más insólita aún: Videla y su esposa, Alicia Raquel Hartridge de Videla, en la ceremonia de inauguración de la semana de productos argentinos en la tienda departamental Matsuzakaya, cortan la cinta que da inicio al evento, rodeados del público que colmaba las instalaciones, entre ellos el canciller japonés Sunao Sonoda. Videla nuevamente de civil y sonriente, parece divertirse como un niño, mientras su mujer, siempre de lentes muy gruesos, lo asiste con diligencia, una pareja de la que en nada nos diferenciamos, tanto usted como yo. Matsuzakaya, tienda ubicada en el corazón de Ginza, el distrito comercial más exclusivo de Tokio, es un símbolo de buen gusto y elegancia frecuentada por las mujeres de la burguesía japonesa. Al igual que en otras tiendas departamentales de prestigio (Mitsukoshi, Isetan, Seibu) periódicamente se ofrecen semanas temáticas de distintos países del mundo, que buscan promocionar sus manufacturas. Argentina en esa ocasión, de acuerdo con The Japan Times, presentó vinos, objetos de plata y cuero, abrigos de piel y alimentos (¿quesos?, ¿yerba mate?, ¿̇alfajores?). La imagen manda el mensaje de que Argentina es un país como cualquier otro del mundo, lo cual habría sido verdad de no estar atravesando entonces por la más sanguinaria etapa represiva de su historia. 
La tercera fotografía, digna de ser comentada, es la que acompaña a la nota del 10 de octubre, arriba reseñada, y que fue tomada en ocasión de la inauguración de la sucursal, en Tokio, del Banco de la Nación Argentina. En ella aparecen el presidente del banco, Juan M. Ocampo, haciendo uso de la palabra, y tres funcionarios argentinos: Luis Manuel Casanova, gerente; Jorge Prat Gay, vicepresidente, y Osvaldo R. Agatiello, el representante argentino en Tokio. Los elementos dignos de ser observados son la bandera argentina, plantada en el primer tercio de la foto, muestra de un nacionalismo impensable en esos días en Japón, donde su enseña nacional seguía asociada a la guerra, y la presencia de un circunspecto sacerdote, vestido con la casulla y un libro de oraciones en la mano, en posición de oficiar misa, el profesor Humberto Cavaliere, vicedirector del Politécnico Saleciano de Argentina, un mensaje más o menos subliminal, al cual no se refiere ninguna de las notas de que Estado e Iglesia marchan de la mano en Argentina.

\section{RECAPITULACIÓN}

La visita de Videla a Japón en 1979 debe ubicarse en el contexto de la Guerra Fría, cuando todavía no se vislumbraba la caída del "socialismo real", que representaba la Unión Soviética. Por el lado argentino, el combate a la subversión, como fue denominada por el Proceso de Reorganización Nacional, con Videla a la cabeza, la brutal represión, inédita en el país, era la pantalla idónea tras la cual ocultar los intereses económicos de los sectores civiles más reaccionarios del país, y su voluntad de implantar un sistema que beneficiara a unos pocos y empobreciera a las mayorías, acabando con las conquistas históricas de la sociedad argentina en su conjunto. Por el lado de Japón, la proximidad de regímenes socialistas como los de la Unión Soviética, China y Corea del Norte; la derrota de Estados Unidos en la Guerra de Vietnam y la convulsionada situación del Sureste de Asia, hacían temer al conservador partido en el gobierno, desde hacía un cuarto de siglo, la pérdida de su hegemonía a favor de la oposición socialista, muy activa entonces.

Recibir a Videla en Japón, cuando su prestigio en el mundo había descendido a los niveles más bajos, por la sistemática violación a los derechos humanos, y que hasta Estados Unidos, con el presidente James Carter a la cabeza, denun- 
ciaba, era una maniobra delicada que había que planificar hasta en sus más mínimos detalles.

Los grandes periódicos japoneses, en líneas generales, recibieron con beneplácito al dictador argentino y su comitiva cívico-militar, pues la misión tuvo un evidente sesgo económico que a todos convenía: en apariencia, lo que interesaba era lograr un equilibrio en el intercambio de productos agrícolas y materias primas argentinos a cambio de tecnología y recursos financieros japoneses. Para ello, era necesario evitar cualquier referencia a temas políticos - más allá del combate al comunismo del que seguramente Videla y Ohira hablaron en privado y que la prensa recogió tímidamente- que pudiera empañar la visita de Videla y poner en alerta a la opinión pública japonesa, para la cual la desastrosa experiencia de la guerra, todavía fresca después de más de 30 años, la hacía poner en guardia frente a todo lo que oliera a cuarteles. Por eso Videla, saliéndose de su papel habitual de dictador uniformado (que ni siquiera evitó cuando asistía a los partidos del Mundial ' 78 a sabiendas de que las cámaras enviarían su imagen al resto del mundo) llegó a Japón, y así se mantuvo durante los 5 días de su visita, vestido de civil, como el gran número de militares de las tres armas y diversos grados que lo acompañaban.

Fue muy sintomático -además de un gran error, desde nuestra perspectiva- declarar a Videla huésped de Estado, al ser alojado en el mismo edificio en el que se hospedaban las grandes personalidades políticas que visitaban Japón. Más grave aún fue que lo recibiera en el Palacio Imperial de Tokio el discutido emperador Hirohito, por su papel en la guerra, olvidada casi ya su imagen uniformada. Tal vez sea por ello que mientras duró la visita, nunca se mostró al dictador en traje militar ni se hizo referencia al grado de teniente general que detentaba Videla (excepto en el mensaje de bienvenida publicado por la empresa Toyota).

Japón fue considerado por el conservadurismo argentino a lo largo del siglo xx como un país lejano y exótico, con explosiones de simpatía hacia él no precisamente vinculadas a la libertad de los pueblos, como sucedió durante la Guerra ruso-japonesa y la Segunda Guerra Mundial. Todo lo relacionado con Japón en Argentina se volvía conservador, así como todo lo relacionado con Argentina en Japón se manejaba desde una perspectiva conservadora. 
La visita de Videla, tal como la documentó el diario The Japan Times, resulta así apasionante, en la medida en que la "ignorancia" mutua de ambos países -real o fingida, y más allá de las simpatías históricas antes mencionadas-llevó a que una sociedad que había tenido, producto de la democracia de posguerra, un formidable éxito económico al que llegó a calificarse de "milagro" y un saludable rechazo a resolver los conflictos por las armas, recibiera con beneplácito a un brutal dictador militar (disfrazado de civil), involucrado en la desaparición de miles de personas, torturas y apropiación de bebés cometidos en los centenares de centros clandestinos de detención. Por lo pronto, una reflexión que surge de la lectura de estos documentos es que las relaciones entre Argentina y Japón parecieran condenadas a quedar siempre en manos de los sectores más conservadores. Hoy, la pregunta obligada es si los japoneses involucrados activamente en la visita de Videla de 1979 estarán enterados de que tanto el dictador como su embajador de entonces están presos, a la espera de ser juzgados por crímenes de lesa humanidad, y que el súper ministro Martínez de Hoz está en la mira de la justicia de su país como responsable de un plan económico que acabó con conquistas históricas de la sociedad argentina para favorecer a unos pocos.

Por último, queda para los psicólogos, sociólogos y antropólogos, desde cada una de estas disciplinas, analizar lo que puede haber significado para la sociedad japonesa la visita de Videla, ya que politólogos, economistas e internacionalistas seguramente han de detectar, con la simple lectura de las notas periodísticas que presentamos a continuación, las razones ocultas detrás de la inocente y pintoresca puesta en escena fraguada entonces por ambos gobiernos.

Recibido: septiembre de 2009.

Aceptado: febrero de 2010. 
ANEXO

\section{DOCUMENTOS}

THE JAPAN TIMES

International Airmail Edition

Miércoles 3 de octubre, 1979 (p. 4).

Doc. I. La misión argentina busca estrechar vínculos con Japón

Carlos Jaime Fraguilo [sic], embajador de Argentina en Japón, dijo aquí el martes que la próxima visita a Japón del presidente argentino Jorge Rafael Videla marcará una nueva era en las relaciones de los dos países.

"La relación entre los dos países ha sido sin duda buena y amistosa, pero no lo suficientemente intensa", dijo el embajador argentino en una conferencia de prensa en la residencia oficial de la Embajada de Argentina en Tokio.

En el pasado, Argentina ha mirado más hacia los países europeos, mientras que Japón ha puesto más énfasis en sus relaciones con otros países de Occidente y América Latina, agregó.

Argentina en la actualidad tiene la alta prioridad de mejorar las relaciones políticas con Japón, dijo el embajador refiriéndose al significado de la visita del presidente a Japón dentro de una semana.

El presidente Videla visitará Japón entre el 8 y el 12 para promover la cooperación económica bilateral y expandir aún más las relaciones diplomáticas entre los dos países.

Durante su estancia en Japón, el presidente se entrevistará con el emperador y la emperatriz, el primer ministro Masayoshi Ohira y otros altos funcionarios del gobierno así como con líderes del mundo empresarial.

Se firmarán varios acuerdos sobre intercambio cultural, introducción de la asistencia técnica japonesa e inversión de capital en tres grandes proyectos que se están llevando a cabo en Argentina.

El gobierno argentino desea invitar a las empresas japonesas a que inviertan en el país de manera permanente, así como a introducir tecnologías y desarrollar recursos naturales del país, concluyó el embajador. 
Lunes 8 de octubre (p. 8).

Doc. II. El presidente de Argentina llega hoy a Japón

Se espera que firme acuerdos para impulsar las relaciones bilaterales

Hoy arriba a Japón el presidente argentino Jorge Rafael Videla, lo cual marca una nueva etapa en las siempre cercanas relaciones entre Argentina y este país.

El presidente Videla llegará a Tokio esta mañana, donde permanecerá como huésped de Estado de Japón hasta el viernes, con el objetivo de promover la cooperación económica bilateral.

Será el segundo jefe de Estado argentino que visita Japón y el primero en 18 años. El presidente Arturo Frondizi fue el primer jefe de Estado argentino que visitó Japón en 1961.

El embajador argentino en Japón, Carlos Jaime Fraguilo [sic] dijo a los reporteros en Tokio la semana pasada que "la relación entre los dos países ha sido siempre buena y amistosa, pero no suficientemente intensa".

En el pasado -agregó-, Argentina ha mirado más hacia los países europeos mientras que Japón ponía énfasis en su relación con otros países de Occidente y de América Latina.

El embajador argentino dijo - al explicar el significado de la visita del presidente a Japón- que Argentina en la actualidad tiene como urgente prioridad mejorar la relación política con este país.

Durante su estancia en Japón, el jefe de Estado argentino mantendrá encuentros con el emperador y la emperatriz, el primer ministro Masayoshi Ohira, así como con líderes del gobierno y empresariales.

De acuerdo con el ministro de relaciones exteriores de Japón, el proyecto se relaciona con la expansión de la acería somisA, de la actual producción anual de 2.5 millones de toneladas a 4.3 millones de toneladas, la electrificación del ferrocarril Roca y el desarrollo de la pesca en la región patagónica.

A lo largo de estos encuentros, el presidente visitante solicitará a Japón que importe más productos agrícolas argentinos - como carne procesada-, para expandir de este modo el volumen del comercio bilateral.

El embajador argentino expresó que el gobierno argentino está interesado en que las empresas japonesas inviertan en el país de manera sostenida y que introduzcan nuevas tecnologías que permitan el desarrollo de los recursos naturales.

El presidente Videla se ha propuesto fomentar la introducción de capital extranjero en el desarrollo económico de Argentina desde que se hizo cargo del gobierno, luego del golpe de 1976 que arrebató la presidencia de la señora Isabel Perón. 
Durante su estancia en Tokio, Videla discutirá y firmará acuerdos sobre la base del intercambio cultural, la introducción de asistencia técnica japonesa y la inversión de capital en tres proyectos mayores que están en vía de concretarse en Argentina.

El presidente y su comitiva visitarán más tarde la región de Kansai ${ }^{11}$ para retornar a su país desde Osaka en la tarde del viernes.

Pie de fotos que acompañan la nota:

1. El presidente argentino Jorge Rafael Videla y su esposa.

2. Profusión de rascacielos en Rosario [con el fondo del río Paraná], el centro económico de Argentina [sic].

3. La Pirámide de Mayo [con el Cabildo y la Avenida de Mayo al fondo], símbolo de la nacionalidad argentina, en Buenos Aires, la metrópoli del hemisferio sur.

${ }^{11}$ Región del occidente de Japón, donde su ubican Kioto, antigua capital, y Osaka, centro industrial y financiero, segunda ciudad de Japón. 
Doc. III. Solicitamos a Japón formar parte del desarrollo

Carlos Jaime Fraguío

Embajador de Argentina

La visita a Japón del presidente argentino general Jorge Rafael Videla es un evento sumamente importante para las relaciones entre los dos países.

Argentina y Japón han consolidado lazos sólidos de sincera amistad y cordial cooperación desde la firma del Tratado de Amistad y Navegación en 1898. Pocos años más tarde comenzó la inmigración de japoneses a Argentina: en la actualidad, en mi país, alrededor de 40 mil personas (en un total de 26 millones) pertenecen a la próspera colectividad japonesa.

A raíz del rápido y exitoso proceso de modernización, mi país se convirtió en el más homogéneo de América Latina, con profundas raíces en Europa, una clase media altamente letrada y un sistema de bienestar social avanzado.

A pesar de las crisis de las últimas décadas, Argentina - con un vasto territorio (el cuarto en tamaño del continente americano) y enormes recursos humanos y naturalesenfrenta la tarea de restaurar la ley y el orden en el marco de una democracia fuerte, así como de construir una economía eficiente basada en el sistema de libre mercado.

Las felices relaciones argentino-japonesas a lo largo de muchos años no son sólo el resultado de coincidencias ocasionales de intereses materiales. Mucho más que ello, son la expresión de un sincero sentimiento de afecto entre los dos pueblos, los cuales, a través de la enorme distancia geográfica, se sienten atraídos como dos polos magnéticos opuestos.

Por ello, creo que, dada la prosperidad que ha alcanzado en años recientes, la capacidad técnica y financiera, así como su gran tradición cultural, podemos solicitar a Japón su participación en los proyectos de países en desarrollo tales como Argentina, seguros de los beneficios mutuos.

El mejoramiento del intercambio comercial (en este sentido, la Cámara de Comercio argentino-japonesa juega un papel significativo), la inversión en varias áreas económicas (como la industria pesquera), la modernización de los ferrocarriles argentinos, la inauguración de la sucursal del Banco de la Nación Argentina en Tokio, la cooperación en ciencia y tecnología, y en asuntos culturales, constituyen algunos de los campos donde es posible profundizar los vínculos entre Argentina y Japón.

Nuestros dos gobiernos creen que los encuentros personales constituyen el camino más apropiado para promover un mejor entendimiento entre países. Agradezco pro- 
GUILLERMO QUARTUCCI

fundamente a las autoridades japonesas por invitar al presidente Videla a realizar esta visita en este mes de octubre.

Foto que acompaña la nota:

1. Carlos Jaime Fraguío, embajador de Argentina en Japón. 
Doc. IV. Colocando la piedra fundamental de una amistad en crecimiento

Shigeo Nagano

Presidente Asociación nipo-argentina

Es un gran privilegio para mí expresar unas palabras en ocasión de la visita a Japón de Su Excelencia, el Sr. Jorge Rafael Videla, presidente de Argentina, junto con su esposa.

Se trata del segundo presidente argentino que visita Japón después de la Segunda Guerra Mundial. Ésta será la segunda vez en 18 años que Japón es visitado por los líderes máximos del país sudamericano.

La visita del presidente Videla a Japón es sumamente oportuna y significativa, considerando que los intercambios entre Japón y Argentina en campos como la economía, la cultura y muchos otros se están intensificando día con día. Estoy totalmente confiado en que esta visita echará las bases del futuro desarrollo, a partir de ahora, de las relaciones entre los dos países.

Geográficamente situados en las antípodas, muy lejos uno del otro, Japón y Argentina han mantenido relaciones económicas, culturales y muchas otras a lo largo de casi un siglo. En particular, los japoneses están sumamente agradecidos a Argentina por el hecho histórico de que buques de guerra como el Nisshin y el Kasuga ${ }^{12}$ cedidos $^{13}$ por Argentina, sirvieron de fuerza impulsora a la victoria de Japón en la Guerra ruso-japonesa.

Asimismo, antes de la Segunda Guerra Mundial, muchos japoneses emigraron a Argentina, donde fueron cálidamente recibidos. En la actualidad, los argentinos de origen japonés se encuentran activos en los campos más variados, contribuyendo en buena medida a aumentar la prosperidad de Argentina.

Las relaciones comerciales entre Japón y Argentina se expanden en escala creciente, con Argentina exportando a Japón productos agrícolas, incluida la carne, y con Japón exportando principalmente maquinaria, plantas industriales y materiales rodantes. Es sumamente alentador que la cooperación de Japón en múltiples y variados proyectos en Argentina esté rindiendo frutos.

${ }^{12}$ Acorazados Nisshin (ex Mariano Moreno) y Kasuga (ex Bernardino Rivadavia), ambos construidos para Argentina en Génova, Italia, en los Astilleros Ansaldo. Fueron "cedidos" por el presidente Julio A. Roca al Imperio de Japón y desempeñaron un papel muy destacado en la derrota del Imperio ruso en la batalla de Port Arthur que definió la victoria japonesa en la Guerra ruso-japonesa de 19041905. El marino argentino Manuel Domecq García estuvo de observador en esa famosa batalla.

${ }^{13}$ El verbo utilizado en inglés es leased, algo así como "arrendar a perpetuidad". En realidad, fueron "comprados" por el gobierno japonés, a espaldas de la Dieta (Parlamento). 
Como es bien sabido, Japón carece de recursos naturales, con un territorio exiguo superpoblado, lo que impulsa al país a subsistir basándose en el comercio exterior. En estas circunstancias, considero que Japón debería pensar seriamente en la situación en que se encuentran sus socios comerciales y en el futuro desarrollo del comercio exterior.

Afortunadamente, las relaciones de amistad entre Japón y Argentina se mantienen firmes desde el pasado. En especial, es una cuestión de gran regocijo para Japón que las relaciones bilaterales se hayan intensificado en años recientes en el campo pesquero gracias a la cooperación de Argentina.

El desarrollo pesquero de Argentina significa un mejor abastecimiento de proteínas para Japón, y confiamos en que el futuro desarrollo de la pesca contribuirá al estrechamiento de las relaciones entre Japón y Argentina.

Para concluir, permítaseme expresar mi más ardiente deseo de que el presidente Videla, durante su visita a Japón, pueda reunirse con la mayor cantidad posible de japoneses de los más variados campos, como el político, económico, social y cultural, para contribuir así a la promoción de un mejor entendimiento y una relación de cooperación más activa entre los dos países.

\section{Foto que acompaña la nota:}

1. Shigeo Nagano, presidente de la Asociación argentino-japonesa.

(p. 9) 
Doc. V. Crecimiento altamente favorable en las inversiones internas guía la actividad económica por el camino de la recuperación

En el primer trimestre de 1979, el producto bruto interno (PIB) de Argentina creció 12\% si se lo compara con el primer trimestre de 1978. No es ningún secreto que la actividad económica sufrió una gran depresión entre enero y marzo de 1978, factor que podría haber empañado algo el brillo de las cifras de 1979. Sin embargo, en términos absolutos, el producto de 1979 es el más alto jamás registrado en los anales económicos de Argentina.

El nivel, expresado en el valor del peso de 1930, alcanzó el monto de $18.1 \mathrm{mil} \mathrm{mi-}$ llones de pesos argentinos, algo superior a los 18.1 mil millones de los tres primeros meses de 1975, hasta ahora el más alto de todos los tiempos.

Es también significativo notar que el piB del primer trimestre de 1979 fue 5.2\% más alto que las cifras de igual periodo de 1977, año de franca recuperación después de la depresión de 1975 y 1976.

Esta recuperación económica es atribuida al desarrollo altamente favorable de la inversión bruta interna y a la conducta positiva de parte de los bienes de consumo.

Estos dos parámetros alcanzaron el muy alto nivel de $18.6 \%$ y $15.6 \%$, respectivamente. Consideradas por separado, ambas cifras constituyen un récord histórico dentro de los registros de los primeros trimestres.

En cuanto a inversiones, los observadores económicos han señalado que las áreas de mayor expansión fueron la construcción y la producción de bienes durables. La construcción creció 12.4\%, mientras que la inversión en bienes durables alcanzó 18.1\%.

En el terreno de bienes de consumo y servicios, las exportaciones cayeron mientras que las importaciones crecieron significativamente. La caída en las exportaciones fue de $4.3 \%$ y las importaciones fueron $27.9 \%$ superiores al primer trimestre de 1978 .

Las cifras para cada sector del desarrollo registraron aumentos, si bien los porcentajes no son constantes. La producción de bienes alcanzó 13.2\% y la de servicios, 10.7\%.

En este sentido, el sector más significativo fue el de la industria manufacturera, que registró 16.6 \% de aumento. En términos absolutos, el volumen de las manufacturas fue el tercero más alto de la década, sólo superado por 1974 y 1975.

Esta conducta del sector en su conjunto se observa también en todos los subsectores. Especialmente activas se mostraron la industria metalúrgica básica y la manufactura de equipos pesados y maquinarias.

Aunque menos dramáticos, pero igualmente auspiciosos, hubo avances en textiles, ropa y cuero, en papel y productos derivados, en la industria editorial y publicaciones, en químicos y petroquímicos, y sustancias derivadas del carbón, el caucho y los plásticos. 
El papel de la industria agrícola y asociados - como producción de alimentos, agricultura, caza, silvicultura y pesca- fue también significativo, con un aumento de $7.9 \%$. En el subsector agrícola el aumento fue particularmente notable y muestra su recuperación luego de la tendencia negativa de 1978, año en el que la cosecha de trigo cayó estrepitosamente y hubo incluso un marcado declive en la producción vitivinícola.

La minería y los yacimientos minerales contribuyeron con $7.8 \%$ al crecimiento del PIB. Esto se debió principalmente al incremento en la producción de petróleo y gas natural, pero también la extracción de minerales ferrosos y no ferrosos creció. El aumento de la producción de carbón mineral fue extremadamente alto.

La industria de la construcción creció en el mismo periodo 9\%. El incremento de la construcción privada fue de $10.7 \%$ y el de la pública, $6 \%$.

En el sector servicios, el incremento fue notable en las áreas más directamente vinculadas a la producción de bienes - como electricidad, gas y agua- donde el crecimiento fue de 14\%; en los comercios al por mayor y menor, hotelería y restaurantes el incremento fue de $12.3 \%$; y en transporte, almacenaje y comunicaciones, de $11.4 \%$.

Por último, la oferta de servicios de las instituciones financieras, compañías de seguros, bienes raíces y servicios comunitarios mostró un crecimiento de $4.2 \%$, y la de los servicios sociales, $9.4 \%$.

El siguiente es un informe detallado del crecimiento de cada sector, en el marco del PIB, el cual, en términos generales, fue de 12\% en los tres primeros meses de 1979.

Agricultura

El valor agregado de este sector fue de 7.9\%. En términos absolutos, es el crecimiento más alto de que se tenga registro. Se obtuvieron resultados positivos en todos los sectores involucrados. Debido a factores estacionales, las estadísticas son abrumadoramente dominadas por los cereales y el lino.

La cosecha de trigo fue de $53 \%$ superior a la del año anterior. También las oleaginosas tuvieron un significativo crecimiento de $23.3 \%$ gracias a la cosecha de la soja.

La ganadería, aunque no alcanzó el impacto de la agricultura, creció $3.1 \%$. Se destacó sobre todo el aumento de $4.1 \%$ de la faena de carne vacuna, de $1.5 \%$ de carne porcina y de $7.3 \%$ en la producción de leche. 
Minería

El crecimiento bruto en minería se aceleró hasta alcanzar 7.8\%. El valor agregado a la economía debido a este factor es el más alto que cualquier otro registrado hasta ahora.

La producción de petróleo y gas natural creció $7.1 \%$. Básicamente, esto se debe a una mayor extracción en los pozos que están en operación.

Las minas de carbón aumentaron su producción $68.9 \%$, mientras que la extracción de minerales no ferrosos creció $8.1 \%$, lo cual se debió a una mayor actividad en la construcción, el principal mercado de estos minerales.

Manufacturas

La industria manufacturera fue la estrella de los primeros tres meses de 1979, con un crecimiento bruto no menor a 16.6\%. En términos absolutos, las cifras de 1979 son las terceras más altas de la década, detrás de 1974 y 1975.

El crecimiento fue general, pero la actividad de cada sector es variable. Los mayores aumentos fueron observados en los sectores más íntimamente relacionados con inversiones tales como la manufactura de metales (29\%) y maquinarias y equipos (25.9\%).

La industria alimenticia, como bebidas y tabaco, creció $1.1 \%$, sobre todo gracias a la producción de harinas y derivados, y aceites comestibles. La carne envasada, que es muy bien recibida en los mercados extranjeros, tuvo también un crecimiento significativo.

La deprimida industria del vestido (textiles, ropa y cuero) se recobró hasta alcanzar un crecimiento de $17.7 \%$.

La industria editorial creció $17.6 \%$, lo cual se atribuye a una mayor inversión en la producción de papel y derivados, y al aumento de la demanda de periódicos y revistas.

En el sector químico, el crecimiento fue de $14.9 \%$, debido sobre todo al aumento de la actividad petroquímica y de los plásticos.

Los minerales no ferrosos alcanzaron 7.6\%, conforme la producción de contenedores de vidrio aumentó. También influyó el crecimiento del sector de la construcción.

El crecimiento de $29 \%$ de la metalurgia básica se sustenta en la creciente producción de hierro primario, acero y, fundamentalmente, productos de herrería. En la actualidad, puede decirse que el mercado interno para estos productos es firme.

En este sector, la rama más activa fue la de maquinaria pesada y equipos, con un incremento de $9 \%$ basado en la industria privada y en los proyectos públicos.

El sector privado de la construcción alcanzó su nivel histórico más alto. El porcen- 
taje alcanzó la cifra de 10.7\% en la construcción de viviendas. La construcción pública creció 6\% debido a la continuación de proyectos iniciados en años anteriores.

Servicios

El valor agregado al pis por la electricidad, gas y agua fue 14\% más alto que en 1978, debido especialmente a una mayor actividad en la generación hidroeléctrica y a la expansión de la red de distribución de gas natural.

Los sectores asociados a la producción de bienes, tales como comercio y transporte, crecieron a tasas similares a la de los bienes involucrados. El incremento fue de 12.3\% para el comercio al menudeo, hotelería y restaurantes, debido a la recuperación de la demanda y a un aumento en las importaciones.

El transporte, almacenamiento y comunicaciones, el incremento fue de $11.4 \%$, gracias al mayor volumen de fletes marítimos y el mayor número de pasajeros en aviones. En el área de las comunicaciones el aumento fue de 7.1\%, especialmente por la mayor actividad de la telefonía (10\%) y de los servicios postales (1.7\%).

Pie de fotos que acompañan la nota:

Vista interior de la cinta de producción de Dálmine Siderca, una de las empresas fabricantes de productos de acero en Argentina.

Manos femeninas argentinas ocupadas en seleccionar la fruta a ser envasada en una planta procesadora de frutas.

Las Cataratas de Iguazú, una de las 275 cascadas que caen desde una altura de 230 pies y que forman una curva de alrededor de dos millas.

Plaza San Martín y río de La Plata [con el Edificio Cavannagh]. 
Martes 9 de octubre (p. 14).

(The Japan Times reproduce una nota editorial del diario Tokyo Shinbun ${ }^{14}$ del día an-

terior)

Comentarios de prensa

Doc. VI. El presidente argentino Jorge Rafael Videla está aquí en una visita como huésped de Estado de cinco días para impulsar más aún los lazos entre los dos países Japón y Argentina han gozado, desde el establecimiento de sus vínculos en 1898, de una buena relación. Las relaciones bilaterales recientemente se intensificaron más aún con la visita a Argentina, en 1967, del príncipe heredero y la princesa. ${ }^{15}$ Asimismo, el ministro de Relaciones Exteriores, Sunao Sonoda, realizó una visita en agosto pasado.

En términos económicos, los dos países se encuentran en una relación complementaria ya que Japón importa algodón y lana de Argentina, mientras que exporta productos de acero y maquinaria al país latinoamericano.

En los últimos trece años, líderes de negocios de ambos países han mantenido en seis ocasiones reuniones comerciales conjuntas con el objetivo de impulsar la cooperación económica.

Sin embargo, hay algunas discrepancias entre lo que Argentina pretende exportar a Japón y lo que Japón en realidad importa. Nosotros, según las enérgicas demandas de Argentina, deberíamos importar de aquel país mayor cantidad de productos, entre ellos trigo y carne. Es muy probable que Japón dependa mucho más, en el futuro, de los alimentos provenientes de Argentina conforme la escasez nos vaya golpeando.

Asimismo, el gobierno japonés debería ser más positivo en el otorgamiento de préstamos destinados a la acería estatal SomISA, tal como se propone solicitar el presidente Videla en sus reuniones con el primer ministro Masayoshi Ohira durante su visita.

Esperamos que el gobierno moderado de Argentina, bajo el liderazgo del presidente Videla, logre alcanzar una mayor estabilidad en su país.

${ }^{14}$ Especialmente leído en el área metropolitana de Tokio, alcanza un tiraje diario de algo menos de 620 mil ejemplares.

${ }^{15}$ Emperador y emperatriz de Japón desde la muerte de Hirohito, en 1988. 
Miércoles 10 de octubre (primera plana).

Doc. VII. El presidente argentino solicita más inversiones

Jorge Rafael Videla, presidente de Argentina que nos visita, solicitó a Japón que incremente la inversión de capital privado en su país para favorecer su desarrollo económico. La demanda fue hecha en ocasión de su primera ronda de conversaciones con el primer ministro de Japón, Masayoshi Ohira, en la casa oficial de huéspedes de Tokio. El presidente está hospedado aquí desde su arribo en una visita oficial de cinco días a Japón.

El presidente explicó que, en años recientes, su administración ha estado trabajando para atraer inversiones extranjeras en amplias áreas de la industria argentina.

A lo largo del encuentro de una hora de duración, Ohira y Videla intercambiaron puntos de vista sobre la situación política de América Latina y Asia, incluyendo a la convulsionada Indochina.

Ohira puntualizó que Japón ha mantenido siempre, y sigue manteniendo, su "diplomacia orientada a la paz" hacia todos los países, incluidas China y la Unión Soviética.

Según un funcionario japonés, el presidente expresó que Argentina se está abocando a la "democratización" de sus instituciones políticas y sociales, y está determinada a servir de "intermediaria" entre el Norte rico y el Sur pobre. 
Doc. VIII. Búsqueda de un acuerdo arancelario

El ministro de Economía de Argentina, José Alfredo Martínez de Hoz, solicitó al ministro de Finanzas Ippei Kaneko que se hagan más expeditas las actuales negociaciones para alcanzar un acuerdo arancelario entre los dos países, según una fuente japonesa del gobierno.

La demanda fue hecha en ocasión de su visita a Kaneko en el Ministerio de Finanzas. También visitó a Masumi Esaki, ministro de Comercio e Industria.

De Hoz asimismo solicitó a Kaneko y Esaki que Japón suministre asistencia financiera y cooperación técnica para la expansión de la acería estatal Sociedad Mixta Siderurgia Argentina [en español en el original, n. del t.] (SOMISA), la electrificación de los trenes suburbanos, el mejoramiento de los sistemas de telecomunicaciones y la construcción de plantas procesadoras de pescado, informó la misma fuente.

(p. 5)

Doc. IX. Argentina gestiona inversiones extranjeras a fin de modernizarse Argentina espera un flujo masivo de inversiones extranjeras para modernizar su estructura industrial. El Dr. Juan M. Ocampo, presidente del estatal Banco de la Nación Argentina, así lo expresó el martes.

Ocampo, que se encuentra con otros funcionarios que acompañan al presidente argentino Jorge Rafael Videla, habló con la prensa en ocasión de la apertura de una sucursal de su banco en Yurakucho. ${ }^{16}$

El lunes, Ocampo firmó un acuerdo con el estatal Banco de Importaciones y Exportaciones de Japón, por el monto de 10 mil millones de yenes, ${ }^{17}$ el cual se destinará a la adquisición de equipos y servicios japoneses que sirvan a los proyectos de desarrollo de Argentina. El mismo día, el banco que preside Ocampo, firmó un acuerdo con el Banco de Tokio por la suma de 1.8 mil millones de yenes ${ }^{18}$ destinados al mismo propósito.

El Banco Central de la República Argentina, otra institución estatal, aprovechó la visita del presidente Videla para firmar acuerdos.

El martes, Ocampo dijo a los hombres de prensa que las inversiones privadas japonesas son bienvenidas en Argentina, especialmente en lo que se refiere a telecomunicaciones y transportes como el ferrocarril, acero y hierro.

${ }^{16}$ Marunouchi-Yurakucho, la City de Tokio, el corazón financiero.

${ }^{17} 45$ millones de dólares, al cambio del momento: 1 dólar $=225$ yenes .

18 millones de dólares. 
GUILLERMO QUARTUCCI

El gobierno de Buenos Aires en 1972 promulgó una ley destinada a atraer la inversión extranjera, informó Ocampo. Hasta marzo de 1977 las inversiones japonesas en Argentina alcanzaban los 30 millones de dólares, concluyó.

Pie de foto que acompaña la nota:

Juan M. Ocampo (centro), presidente de la junta directiva del Banco de la Nación Argentina, encabeza el martes la ceremonia inaugural de la primera sucursal en Tokio. También estuvieron presentes (de izquierda a derecha): Luis Manuel Casanova, gerente; Jorge de Prat Gay, vicepresidente; Prof. Humberto Cavaliere, vicedirector del Politécnico Saleciano, y Osvaldo R. Agatiello, representante del banco argentino en Tokio. La dirección es: Oficina 1901, Yurakucho Denki Building-N, Yurakucho 1 chome, Chiyoda-ku, Tokio 100. 
Viernes 12 de octubre (primera plana).

Doc. X. Videla y Ohira acuerdan incrementar la "sociedad" en varias áreas El presidente de Argentina Jorge Rafael Videla, de visita en Japón, y el primer ministro Masayoshi Ohira acordaron el jueves que los dos países cooperarán como "socios" no sólo en el campo económico, sino también en el área política.

Videla se entrevistó en una segunda ronda con Ohira, en la residencia oficial de este último, para discutir asuntos de cooperación económica bilateral, incluyendo la inversión privada japonesa en Argentina.

A lo largo del encuentro de una hora de duración, Videla expresó satisfacción por los resultados de su visita a este país, según fuentes oficiales. Más tarde, el presidente dijo a los reporteros en un encuentro en el Club Nacional de Prensa ${ }^{19}$ que su visita a Japón fue "de lo más fructífera" y que gracias a ésta había llegado a entender mejor al pueblo japonés y su problemática.

El jueves, ambos países firmaron dos acuerdos, el primero para la promoción del intercambio cultural y el segundo para concretar la cooperación tecnológica de Japón.

Ohira le expresó a Videla que Japón estaba decidido a reforzar aún más su relación de verdaderos "amigos" [en español en el original, $n$. del t.] con Argentina.

Videla extendió una invitación a Ohira para visitar Argentina lo antes posible y Ohira aceptó, según un funcionario japonés.

El presidente argentino concluyó su agenda formal en Tokio con un comunicado conjunto con el primer ministro y se dirigió a la región de Kansai el jueves por la tarde. Hoy tiene planeado regresar a su país.

De acuerdo con el comunicado conjunto, Japón enviará el mes próximo a Argentina una misión puntual para que estudie la viabilidad de cooperar financieramente en los planes de incremento de la capacidad productiva de la acería estatal somisa, así como otros proyectos económicos.

La cooperación acordada entre los dos países incluye también la electrificación de la línea Roca de ferrocarril, el mejoramiento de las redes de telecomunicaciones y la construcción de plantas procesadoras de pescado en Argentina.

Japón promete en el comunicado hacer todos los esfuerzos posibles para satisfacer las demandas argentinas de incrementar la importación de trigo, carne procesada y cítricos.

${ }^{19}$ Nihon Kisha Kurabu (Club de Prensa de Japón), lugar donde se reúnen habitualmente los reporteros japoneses con los visitantes distinguidos que llegan al país. 
GUILLERMO QUARTUCCI

De acuerdo con el acuerdo tecnológico firmado el jueves, Japón recibirá argentinos para que sean entrenados en Japón y enviará expertos, préstamos, maquinaria y equipos al país sudamericano.

Argentina, por su parte, brindará trato privilegiado y facilidades al personal japonés que participe en los proyectos de cooperación tecnológica, esto también según el acuerdo.

Pie de foto que acompaña la nota:

El primer ministro Masayoshi Ohira (segundo de la derecha) y el presidente argentino Jorge Rafael Videla (segundo de la izquierda) mantuvieron el jueves la segunda y última ronda de conversaciones en la oficina de Ohira. También estuvieron presentes el ministro de Relaciones Exteriores Sunao Sonoda (extrema derecha) y su contraparte argentina Carlos Washington Pastor (extrema izquierda). 
Sábado 13 de octubre (p. 12).

(The Japan Times reproduce una nota editorial del diario Mainichi Shinbun ${ }^{20}$ del día anterior)

Comentarios de la prensa

Doc. XI. La amistad con Argentina

El presidente de Argentina Jorge Rafael Videla realizó una visita formal de 5 días y discutió varios proyectos de cooperación económica y las vías de promover las tradicionalmente amistosas relaciones entre los dos países.

Creemos que la visita, la primera de una presidente argentino en 18 años, prueba que se trata del comienzo de una nueva era en nuestras relaciones bilaterales basadas en la interdependencia, especialmente en el campo económico.

Esperamos que ambos países desarrollen en el futuro la relación económica a través de proyectos para los cuales ha sido prometida la cooperación de Japón, incluidas la expansión de los ferrocarriles y la construcción de plantas procesadoras de pescado en Argentina.

El gobierno japonés debería especialmente hacer esfuerzos para estimular a las empresas privadas a que inviertan en la acería somisA, como ha sido solicitado por el gobierno argentino.

Japón debería asimismo hacer esfuerzos positivos para promover la importación de alimentos provenientes de Argentina, a pesar de algunos problemas concernientes a la calidad de la carne, como la fiebre aftosa, y del trigo.

Argentina ha venido enfrentando grandes dificultades en tratar de superar, con el régimen militar que tomó el poder en 1976, la alta inflación, así como la inestabilidad política y social.

El régimen militar ha ido ganando paulatinamente el reconocimiento de otros países conforme su situación se iba estabilizando.

Nos complace sobremanera que nuestro gobierno esté tratando de profundizar la amistad con países latinoamericanos que poseen un gran potencial.

Traducción y notas: Guillermo Quartucci

${ }^{20}$ Tercer diario en tiraje de Japón, con una circulación diaria de 4 millones de ejemplares. Le preceden el Yomiuri Sinbun y el Asabi Shinbun. 